immediately be referred for expert opinion even if she has no symptoms. All women of child-bearing age with a mitral valve diameter of $1.5 \mathrm{~cm}$. or less require close supervision, and if they become pregnant it is safest to undertake valvotomy.

REFERENCES

Bannister, R. G. (1960). Lancet, 2, 329.

Davies, L. G., Goodwin, J. F., Steiner, R. E., and Van Leuven, B. D. (1953). Brit. Heart \%., 15, 393.

Ellis, L. B., Harken, D. E., and Black, H. (1959). Circulation, 19, 803. Emanuel, R. (1963). Brit. Heart 9., 25, 119.

Gilbert, R., Auchincloss, J. H., and Epifano, L. (1963). Amer. f. Med., 34, 452 .

Gilchrist, A. R. (1963). Brit. med. 7., 1, 209.

Goodwin, J. F., Hunter, J. D., Cleland, W. P., Davies, L. G., and Steiner, R. E. (1955). Ibid., 2, 573.

Hargreaves, T. (1961). Ibid., 2, 342.
Harris, E. A. (1958). Lancet, 2, 409.

Hugenholtz, P. G., Ryan, T. J., Stein, S. W., and Abelmann, W. H. (1962). Amer. F. Cardiol., 10, 773.

Kerley, P. (1933). Brit. med.' $7 ., 2,594$.

Likoff, W. (1963). Amer. F. Cardiol., 12, 11.

Lowther, C. P., and Turner, R. W. D. (1962). Brit. med. F., 1, 1027.

Ministry of Health (1963). Report on Public Health and Medical Subjects, No. 108. H.M.S.O., London.

New York Heart Association (1953). Nomenclature and Criteria for Diagnosis of Diseases of the Heart and Blood Vessels, 5th ed. N.Y.H.A., New York.

Priest, E. A., Finlayson, J. K., and Short, D. S. (1962). Prog. cardiovasc. Dis., 5, 219.

Sellors, T. H., Bedford, D. E., and Somerville, W. (1953). Brit. med. F., 2, 1059.

Short, D. S. (1955). Brit. Heart F., 17, 33.

(1956). Ibid., 18, 233.

— and Brunnen, P.'L. (1963). Ibid., 25, 695.

Wells, B. (1954). Ibid., 16, 261.

Wood, P. (1954). Brit. med. Э., 1, 1051, 1113.

(1956). Diseases of the Heart and Circulation, 2nd ed. Eyre and Spottiswoode, London.

\title{
Urinary $\Delta^{16}$-Androsten-3a-ol, 17-Oxosteroids and Mental Illness
}

\author{
B. W. L. BROOKSBANK,* B.SC., PH.D. ; W. PRYSE-PHILLIPS†, M.B., B.S.
}

Brit. med. F., 1964, 1, 1602-1606

Although recognized for some time as a quantitatively prominent steroid in urine (Brooksbank and Haslewood, 1950, 1961), the biological significance of $\Delta^{16}$-androsten-3 $\alpha$-ol (androstenol) (see Formula) remains unknown. It is probably not primarily of peripheral origin in man, nor specifically derived from testosterone (Brooksbank, 1962a; Bulbrook, Thomas, and Brooksbank, 1963 ; Wilson, Lipsett, and Korenman, 1963), but stimulation tests and in vitro studies (Gower and Haslewood, 1961 ; Gower, 1963) have shown that it is formed in the androgen-secreting glands, the adrenal cortex and testis; its biosynthesis by ovarian tissue has not yet been<smiles>CC12C=CCC1C1CCC3CC(O)CCC3(C)C1CC2</smiles>

investigated. The urinary excretion rate of androstenol in adult men is about double that in adult women; the rate falls off in the elderly and is minimal in children. The production of androstenol is therefore closely associated with that of androgens. The greater difference between the sexes in mean androstenol levels than that of mean 17-oxosteroid (17-KS) levels in urine suggests a more direct association of androstenol with testosterone production, but there is no direct evidence for this and the relations are clearly more complex. A low urinary output of androstenol does not appear to be incompatible with essentially normal development of a masculine physique.

\footnotetext{
* Lecturer, Department of Biochemistry and Chemistry, Guy's Hospital Medical School, London.

t Formerly Resident Medical Officer, Department of Psychological Medicine, Guy's Hospital, London. Present appointment: Research
} Fellow, Department of Psychiatry, University of Birmingham.
It has been observed that individual human subjects display characteristic urinary excretion patterns of certain steroids, varying little from day to day and to some extent genetically determined (Dobriner, 1954 ; Kappas and Gallagher, 1960). Individual fluctuations of urinary androstenol levels are relatively slight compared with the range of variation between individuals (Brooksbank, 1962a), and therefore it seemed that androstenol levels could also be regarded as a constitutional parameter. There is an extensive literature on endocrine abnormalities in mental illness (Bleuler, 1954 ; Sands, 1957 ; Reiss, 1958), and there is evidence indicating that deficiency of gonadal secretions is not only a secondary outcome of mental illness but also a predisposing factor of a constitutional nature. It was therefore thought worth while to examine the urinary excretion of androstenol of psychiatric patients and to compare it with that of 17-oxosteroids (17-KS). Initial results, outlined in a preliminary not (Brooksbank, 1962b), showed that a substantially greater proportion of young male psychiatric patients exhibited low urinary androstenol levels than was apparent in the control series of men not under treatment for mental illness. This paper describes the extension and amplification of this survey.

\section{Chemical Methods}

Urinary $\Delta^{16}$-androsten-3 $\alpha$-ol was estimated by the method of Brooksbank and Haslewood (1961), with one small modification which simplified the technique. The urine samples after incubation with $\beta$-glucuronidase were extracted with light petroleum (b.p. $80-100^{\circ}$ C.) (May and Baker, redistilled). The resulting extracts did not need to be washed with aqueous alkali or water before evaporation and chromatography. Agreement was excellent with parallel estimations made employing the published extraction procedure with ethyl ether.

Urinary 17-oxosteroids (17-KS) were estimated by a standard method (Medical Research Council, 1963), involving hydrolysis of steroid conjugates by boiling with mineral acid.

Creatinine in urine was estimated by a standard method (Hawk, Oser, and Summerson, 1947). Steroid excretion rates 
were calculated in terms of 24-hour urine volume, and, except with a number of the controls and four of the patients in whose urine the creatinine was not measured, in terms of grammes of creatinine.

\section{Selection and Psychiatric Assessment of Subjects}

In view of the relatively low levels of androstenol excretion observed in healthy women and in men aged over about 45 , this investigation was confined to male subjects aged 18 to 45 .

The control group consisted of 112 physically healthy men within this age-bracket, men who at the time of urine collection were not receiving psychiatric treatment. This group included subjects (mainly students) whose androstenol excretion had already been determined and reported (Brooksbank, 1962a), supplemented by others (hospital and laboratory staff and their friends) selected to fill out the age-range 18 to 45 years more fully.

The patients consisted of 28 in-patients and 15 out-patients of the Department of Psychological Medicine, Guy's Hospital, and 26 in-patients from other mental hospitals. Urine specimens were obtained from any male psychiatric patient aged 18 to 45 : data were subsequently excluded from the series only if (a) there was evidence that the urine specimen was not collected over 24 hours, or (b) the patient was physically ill or emaciated, or in whom a psychiatric illness with an organic basis, including epilepsy, was diagnosed.

Assessment of the patients was made by one of us (W. P.-P.) from the notes made by the physicians in charge and, with twothirds of the patients, also by personal interview. The presence or absence of specific signs and symptoms was recorded, but in fact it was not found possible to group the patients reliably by analysis of symptoms, and eventually they were grouped in terms of the diagnosis made by the consultant psychiatrist in charge of the case. In searching for possible correlations with androstenol excretion rate other factors were, however, considered-namely, social class, marital state, duration of symptoms, general physique (including physical maturity), clinical state, and treatment, and, when ascertainable, premorbid personality and family history of mental illness. No obvious trends were detected in the relations between any of these factors and urinary androstenol levels, and therefore no attempt was made to analyse fully these possible relations by statistical methods.

The unit providing most of the patients studied had a comparatively high number with puzzling illnesses who had been referred for further investigations, and this factor is reflected in the way in which the patients were grouped, as follows:

A. Schizophrenics (number, 19 ; aged $21-45$, median age 30 years).-Patients in whom the diagnosis of schizophrenia was unequivocal.

B. Probable Schizophrenics (number, 14 ; aged 21-44, median age 30 years).- In these patients the diagnosis of schizophrenia was thought to be likely but not firmly established: a diagnosis of personality disorder or neurosis was insufficient to explain the clinical features. This group is really an extension of group A but is mentioned separately because there was some doubt over the final diagnosis. Group B is combined with group A in the statistical comparisons.

C. Non-schizophrenics (number, 36 ; aged $20-45$, median age 30 years).-Patients with clinical features of neurosis or personality disorder but no signs of any schizophrenic process.

Most of the subjects studied were having at least two drugs and/or other forms of treatment, which were often changed during their stay in hospital. No patient had been in bed for longer than three days, and all were up all day when the specimen was collected. The hospital diet taken was not fully investigated, but the food eaten by most of the Guy's Hospital in-patients was more than adequate in amount and content and was taken in full. However, at the other hospitals we did not take into account the factor of diet.

\section{Differences Between Control and Patient Groups}

In all the distribution curves where more than one urine was analysed from the same subject the mean values for steroid excretion are plotted. The distribution curve for the control subjects is given in Fig. 1. Although the correlation coefficient for the control series, $r=-0.24(P=0.01-0.02)$, between urinary androstenol (mg./24 hr.) and age (yr.) was significant, the slope of the regression line, $y=1.33-0.0034 x$, was so flat and its standard error was so great $( \pm 0.0065)$ that it was clearly unnecessary to attempt to correct for age the urinary androstenol figures for the patients. The corresponding correlation coefficients for schizophrenic (groups A and B) and nonschizophrenic (group C) groups were -0.19 and -0.34 ; only in group $\mathrm{C}$ was the correlation marginally significant $(\mathbf{P}=0.05-0.1)$

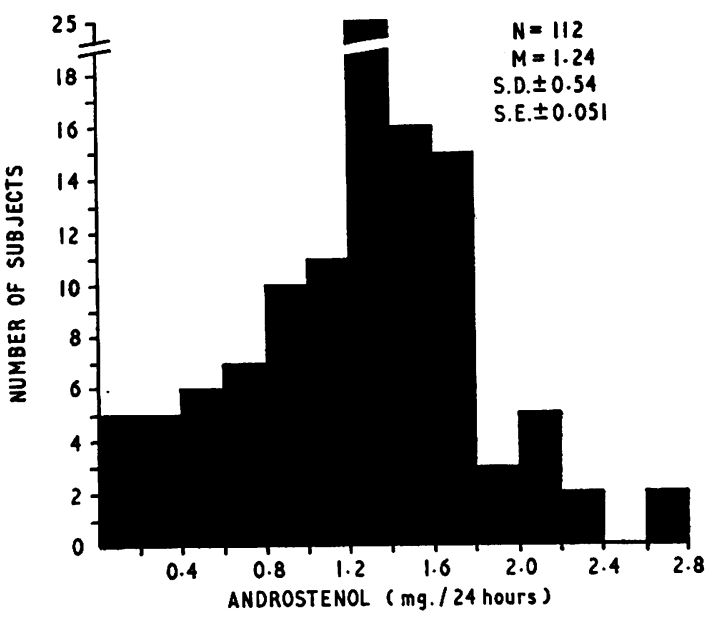

Fig. 1-Frequency distribution curve for urinary androstenol excretion rate in healthy male controls, aged 18 to 45 .

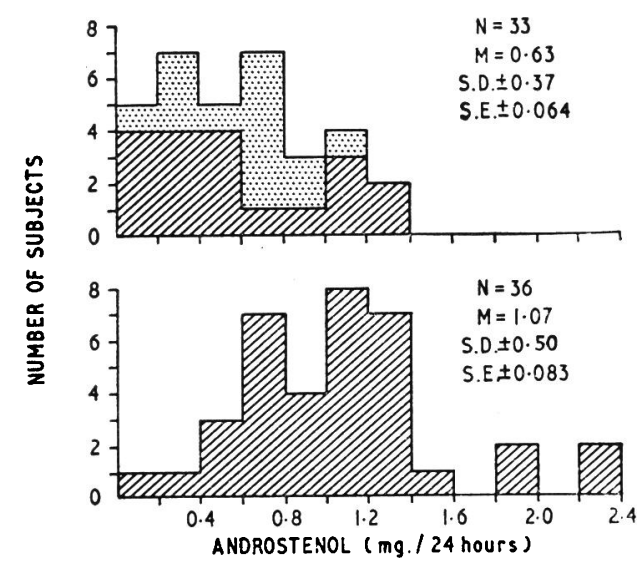

Fig. 2.-Frequency distribution curves for urinary androstenol excretion rate in male psychiatric patients, aged 18 to 45 . Upper curve: striped, group A ; dotted, group B, added to group A frequencies. Lower curve: group C.

The distribution curves for the patient group as a whole and for the seperated schizophrenic and non-schizophrenic groups are shown in Fig. 2. In Table I are set out the corresponding means and standard errors for urinary androstenol of these groups expressed as mg. $/ 24 \mathrm{hr}$. together with the figures for urinary 17-oxosteroids (17-KS), and for both androstenol and 17-KS expressed as $\mathrm{mg} . / \mathrm{g}$. creatinine.

It will be seen from the distribution curves and from the data of Table I that the urinary excretion of androstenol, but 
TAble I.-Urinary Excretion of Androstenol and 17-Oxosteroids in Healthy Men and Male Psychiatric Patients, Aged 18-45 Years

\begin{tabular}{|c|c|c|c|c|c|c|c|c|c|c|c|c|c|c|}
\hline & \multicolumn{4}{|c|}{$\begin{array}{l}\text { Androstenol } \\
\text { (mg./24 hr.) }\end{array}$} & \multicolumn{4}{|c|}{$\begin{array}{c}\text { Androstenol } \\
\text { (mg./g. Creatinine) }\end{array}$} & \multicolumn{3}{|c|}{$\begin{array}{l}\text { 17-Oxosteroids } \\
\text { (mg./24 hr.) }\end{array}$} & \multicolumn{3}{|c|}{$\begin{array}{c}\text { 17-Oxosteroids } \\
\text { (mg./g. Creatinine) }\end{array}$} \\
\hline & $\mid \begin{array}{l}\text { No. of } \\
\text { Subjects }\end{array}$ & Mean & Range & S.E. & $\begin{array}{l}\text { No. of } \\
\text { Subjects }\end{array}$ & Mean & Range & S.E. & $\begin{array}{l}\text { No. of } \\
\text { Subjects }\end{array}$ & Mean & Range & $\begin{array}{l}\text { No. of } \\
\text { Subjects }\end{array}$ & Mean & Range \\
\hline
\end{tabular}

not that of $17-\mathrm{KS}$, expressed in terms either of $\mathrm{mg} . / 24 \mathrm{hr}$. or of $\mathrm{mg}$./g. creatinine, is lower in the patient group than in the control group, and that most of this difference is accounted for by the low levels of urinary androstenol encountered in schizophrenics. Table II shows the statistical significance of differences between means. The distribution curves are not strictly normal, but their deviation from normality was thought not to be sufficient to invalidate tests for significance of differences between means, or correlation coefficients (cf. Mather, 1949).

TABLE II.-Urinary Androstenol; Significance of Differences Between Means

\begin{tabular}{l|l|l}
\hline & \multicolumn{1}{|c|}{$M g . / 24 \mathrm{hr}}$. & \multicolumn{1}{|c}{$\mathrm{Mg}$./g. Creatinine } \\
\hline $\begin{array}{l}\text { All patients } v \text {. controls } \\
\text { Schizophrenics } v \text {. controls } \because\end{array}$ & $\begin{array}{l}\mathrm{t}=4.9, \mathrm{P}<0.001 \\
\mathrm{t}=5.0, \mathrm{P}<0.001\end{array}$ & $\begin{array}{l}\mathrm{t}=3.0, \mathrm{P}=0.001 \text { to } 0.01 \\
\mathrm{t}=3.8, \mathrm{P}<0.001\end{array}$ \\
$\begin{array}{l}\text { All schizophrenics (groups } \mathrm{A} \\
\text { and } \mathrm{B} \text { ) } v \text {. non-schizophrenics }\end{array}$ & $\mathrm{t}=4.2, \mathrm{P}<0.001$ \\
$\begin{array}{l}\text { Non-schizophrenics } v \text {. controls } \\
\mathrm{t}=2.2, \mathrm{P}=0.02 \text { to } 0.05\end{array}$ & $\begin{array}{l}\mathrm{t}=2.4, \mathrm{P}=0.01 \text { to } 0.02 \\
\mathrm{t}=1.3, \mathrm{P}=0.1 \text { to } 0.2\end{array}$ \\
\hline
\end{tabular}

The differences in androstenol excretion between the groups are less when expressed per gramme of creatinine, owing to the tendency for creatinine excretion to be lower in the schizophrenic group, but the differences are still significant at below the $2 \%$ level. It might be objected that the lower apparent creatinine output in the schizophrenic group was due to a lesser reliability of the 24-hour urine collections with these patients. However, the occasional urine collections which were obviously incomplete, taking into account total volume, specific gravity, and total creatinine, were excluded from the series where steroid excretion was expressed as mg. $/ 24 \mathrm{hr}$., though some specimens were included in the $\mathrm{mg}$. $/ \mathrm{g}$. creatinine series. Moreover, the urinary $17-\mathrm{KS}$ in $\mathrm{mg}$./g. creatinine tended to be higher in the schizophrenic than in the non-schizophrenic group, which would not be expected if a large proportion of the 24-hour collections were incomplete. In fact, a tendency to low urinary creatinine output in schizophrenics has been reported in the past (Pincus, Hoagland, Freeman, Elmadjian, and Romanoff, 1949). This is confirmed in our series, where the 24-hour urinary creatinine output figures were 1.39 (S.E. $= \pm$ $0.035)$ for the schizophrenics and $1.65($ S.E. $= \pm 0.028)$ for the non-schizophrenics.

If the whole series of patients is arranged in descending order of urinary androstenol levels and divided into quartiles, the proportions of the total number in each quartile who were definitely or probably schizophrenic (groups $\mathrm{A}$ and $\mathrm{B}$ ) patients are: $18 \%$, $35 \%, 59 \%$, and $78 \%$ respectively in the first, second, third, and fourth quartiles.

The tendency for schizophrenics to exhibit low urinary androstenol levels would be even more striking if some incidental clinical observations were taken into account. Firstly, all four of the men diagnosed as having schizophrenia simplex -that is, shallowness of emotional response, indifference, and impairment of will and drive without catatonia, hallucinations, or delusions-had normal androstenol levels. Secondly, two subjects in this series excreting small amounts of androstenol and diagnosed at the time as suffering from affective illness or personality disorder with no evidence of schizophrenia, did in fact exhibit signs of schizophrenia a year and six months later respectively: a third man, also having little androstenol in the urine, who was regarded at the time as having a personality disorder only, later was learnt to have had a classical schizophrenic illness four years before.

\section{Individual Variation}

In order to test for fluctuation in urinary steroid excretion within individuals, 24-hour urines were collected from some of the subjects on two or more occasions. Twenty-four control subjects and 18 psychiatric patients were tested in this way. The former included 12 students who were tested at approximately 18 weeks and again one week before they sat the 2 nd M.B. examination, to determine whether anxiety was affecting urinary androstenol levels. There was no evidence of any association between emotional stress in these students and androstenol excretion, though the latter rose significantly with five of the students between the two occasions of testing. Eight of the patients were tested directly after admission and again just before discharge from hospital (a mean interval of 45 days), another nine on two occasions during their illness (interval 6 to 62 days, median interval 18 days), and one patient on two occasions with an interval of 489 days.

The data are set out in Table III. It is clear that variations in the daily excretion rate of androstenol in one individual are in general much less than the differences in the rate between individuals. If these data are subjected to analysis of variance, an intra-class, or reliability coefficient, $r_{i}$, can be calculated (Snedecor, 1956), giving a measure of the reliability of one value for the excretion rate being representative of the characteristic excretion rate of that individual ; the maximum value for the

\begin{tabular}{|c|c|c|c|c|c|c|}
\hline \multicolumn{3}{|c|}{$\begin{array}{r}\text { TABLE III.-Vari } \\
\text { Controls } \\
\end{array}$} & & & tients & ithin \\
\hline \multicolumn{2}{|c|}{$\begin{array}{l}\text { Androstenol } \\
(\mathrm{mg} . / 24 \mathrm{hr} .)\end{array}$} & \multirow{2}{*}{$\begin{array}{l}\text { Interval } \\
\text { Between } \\
\text { Tests }\end{array}$} & $\underset{(m}{A n}$ & $\begin{array}{l}\text { nol } \\
\text { hr.) }\end{array}$ & \multirow[t]{2}{*}{ Group } & \multirow{2}{*}{$\begin{array}{c}\text { Interval } \\
\text { Between } \\
\text { Tests } \\
\text { (Days) }\end{array}$} \\
\hline $1 \mathrm{st}$ & 2nd & & $1 \mathrm{st}$ & 2nd & & \\
\hline $\begin{array}{l}1.00 \\
1.58 \\
2.68 \\
1.34 \\
1.35 \\
1.60 \\
0.78 \\
1.25 \\
1.43 \\
1.40 \\
1.56 \\
1.01\end{array}$ & 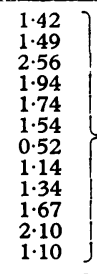 & \multirow[t]{2}{*}{$\begin{array}{l}\text { About } 120 \\
\text { days; } \\
\text { second test } \\
\text { just prior to } \\
\text { 2nd M.B. } \\
\text { examination }\end{array}$} & $\begin{array}{l}1.00 \\
0.18 \\
0.13 \\
0.37 \\
0.79 \\
0.26 \\
1.22 \\
1.93 \\
1.07 \\
2.00 \\
0.66 \\
1.28 \\
0.97\end{array}$ & $\begin{array}{l}1.63 \\
0.33 \\
0.25 \\
0.09 \\
0.81 \\
0.31 \dagger \\
0.95 \\
1.93 \\
0.51 \\
1.93 \\
0.29 * \\
1.01\end{array}$ & $\begin{array}{c}\text { A } \\
\text { A } \\
\text { A } \\
\text { A, aged } 54 \\
\text { B } \\
\text { B } \\
\text { B } \\
\text { C } \\
\text { C } \\
\text { C } \\
\text { C } \\
\text { C }\end{array}$ & $\begin{array}{c}18 \\
29 \\
489 \\
7 \\
6 \\
19 \\
62 \ddagger \\
6 \\
8 \\
26 \ddagger \\
50 \ddagger \\
61 \ddagger\end{array}$ \\
\hline \multirow{2}{*}{\multicolumn{2}{|c|}{ 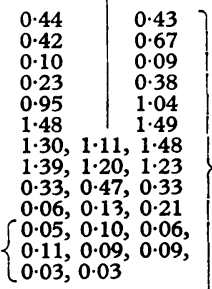 }} & & $\begin{array}{l}0.67 \\
0.35 \\
0.41 \\
0.21 \\
0.22 \\
1.01\end{array}$ & $\begin{array}{l}0.52 \\
0.36 \\
0.26 \\
0.48 \\
0.22 \\
1 \cdot 10\end{array}$ & 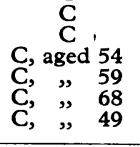 & $\begin{array}{l}62 \ddagger \\
62 \ddagger \\
10 \\
21 \ddagger \\
26 \ddagger \\
50 \ddagger \\
\end{array}$ \\
\hline & & \multirow{2}{*}{$\begin{array}{l}\text { Intervals } \\
\text { ranged from } \\
1 \text { day to } \\
29 \text { months }\end{array}$} & \multirow{2}{*}{\multicolumn{4}{|c|}{$\begin{array}{l}* 0.27 \mathrm{mg} . / 24 \mathrm{hr} . \text { after } 24 \text { days. } \\
+0.32 \mathrm{mg} . / 24 \mathrm{hr} \text {. after } 15 \text { days. } \\
\ddagger \text { Tested on admission and discharge. }\end{array}$}} \\
\hline \multicolumn{2}{|c|}{$\begin{array}{lll}0.49, & 0.17, & 0.42 \\
0.20, & 0.52, & 0.64, \\
0.55 & \end{array}$} & & & & & \\
\hline
\end{tabular}


coefficient is of course 1.0. For the androstenol data $r_{i}$ was found to be 0.97 for the controls (aged 18 to 45 ) and 0.89 for the patients $(0.86$ if the five patients aged over 45 were excluded). The group of controls tested for variability include a greater proportion of habitually low androstenol excreters than observed in the control group as a whole: the relative constancy of their androstenol output is demonstrated, but the result of including them may of course have been to increase the betweensubject variance. The corresponding figures for $r_{i}$ calculated from repeated 17-KS excretion data were 0.54 for controls and 0.55 for patients; as with the androstenol variation data, the $17-\mathrm{KS}$ figure for the controls included those of the 12 subjects tested far from and just before their 2 nd M.B. examination.

\section{Androstenol Excretion and Constitution}

In 65 individuals of the control group the androstenol excretion rate was correlated significantly with body surface area $(\mathrm{r}=0.41, \mathrm{P}<0.001)$ and with weight $(\mathrm{r}=0.36, \mathrm{P}<0.001)$, but it was not correlated with extraversion or neuroticism scores by the Maudsley personality inventory (Eysenck, 1959).

Only for 17 patients ( 7 schizophrenics, 10 non-schizophrenics) were figures for body surface area available; the mean urinary androstenol for this group was $0.97 \mathrm{mg} . / 24 \mathrm{hr}$. (range, $0.13-2.28$ ), and the correlation with body surface area was not significant. In 19 individuals of the control group tested, the androgyny score (Tanner, 1955), measured by Dr. A. J. Coppen in connexion with another investigation, was found not to be correlated with urinary androstenol levels.

\section{Relation Between Androstenol and 17-Oxosteroids}

The urinary androstenol and 17-KS figures were plotted against each other, for the separate control and patient groups, and regressions were calculated. (In doing so the repeated analyses on the same individual subjects were entered separately, and therefore the regressions included within-subject as well as between-subject covariance.) Assuming a linear relation between the excretion rates of androstenol and 17-KS, the correlation coefficients, $r$, were found to be 0.45 for the controls, 0.64 for the schizophrenics, 0.52 for the non-schizophrenics, and 0.53 for the combined patient group. However, the plot of androstenol against $17-\mathrm{KS}$ (mg./24 hr.) indicated that the relation between the two parameters was not linear. But when the difference $(\mathrm{z})$, between the observed value for androstenol (y) and that calculated $\left(y_{0}\right)$ from the regression line on 17-KS, was plotted against the observed value (y) an interesting linear relation appeared for both the control and patient groups. From these latter plots the following correlation coefficients, $\dot{r}$, were obtained for $z$ against $y: 0.89$ for the controls, 0.68 for the schizophrenics, 0.89 for the non-schizophrenics. The fact that $\dot{r}$ is a litle lower for the schizophrenic group than for the others may only be due to the greater inaccuracy of the androstenol measurements at low levels of androstenol, but it could also be an expression of the more erratic co-ordination of endocrine function which tends to be associated with schizophrenia. At any rate, for all groups, when the output of androstenol was low it was lower than that calculated from the linear regression on 17-KS, and when high it was higher than that calculated. It seems probable that the urinary output of androstenol is an exponential or polynomial function of the output of $17-\mathrm{KS}$; if so, this may be of considerable biological importance, as discussed below.

\section{Discussion}

The observations recorded here on the mathematical relation between urinary androstenol and 17-KS excretion rates suggest that a low level of androstenol in the urine may indicate a "subclinical" androgen deficiency, whether it is associated with mental illness or not. Thus while urinary 17-KS levels are believed to be related in a direct fashion to the quantity of biologically active androgens of all kinds, including dehydroepiandrosterone, released into the circulation by glands secreting steroid hormones, the production of 16-dehydro $\mathrm{C}_{19}$ steroids, such as androstenol, may be a side-reaction which becomes of greater importance at high production rates of androgens and then might tend to set a limit to the rate of their release, as has been suggested by Stylianou, Forchielli, and Dorfman (1961). Conversely, at low rates of production of androgens, this postulated "safety-valve" mechanism of 16-dehydrosteroid formation would not be operating. If this is so, the excretion rate of androstenol would be a more sensitive indication than that of $17-\mathrm{KS}$ of the glandular secretion rate of androgens as a whole, and not of course necessarily of testosterone in particular.

The marked tendency towards low urinary androstenol levels in patients showing signs of schizophrenic psychoses corresponds with the observations so often reported of an increased incidence of physical or psychological signs of androgen lack in such patients-see, for example, Hoskins (1943), Bleuler (1954), Sands (1957), Reiss (1958), Rey and Coppen (1959). The mean excretion rate of $17-\mathrm{KS}$, on the other hand, in our series of patients is not abnormally low, the distribution of the data conforming to those reported by others. Thus in schizophrenia in general the urinary 17-KS levels have been found not to be abnormal on average, but to vary more widely than in normal subjects both between different patients and in individual patients from time to time (Bleuler, 1954 ; Sands, 1957). Evidence of a constitutional abnormality of steroid metabolism in mental illness has generally been lacking hitherto, though in certain groups of patients, such as the inadequate or immature type (Batt, Kay, Reiss, and Sands, 1957), or female patients with irregular menstrual cycles or amenorrhoea (Rey, Nicholson-Bailey, and Trappl, 1957), urinary 17-KS levels tend to be low. Abnormalities in the excretion rate of androgenic activity or of particular androgen metabolites in the urine of some psychotic patients have been reported in the past (Hoskins and Pincus, 1949 ; Mittelman, Romanoff, Pincus, and Hoagland, 1952 ; Reiss and Stitch, 1954 ; Wakoh, 1959 ; Hatotani, Ishida, Maeda, and Waka, 1960), but the findings do not seem to have demonstrated any more consistent endocrine disorders in mental illness than have the results of urinary $17-\mathrm{KS}$ estimations.

Low levels of $17-\mathrm{KS}$ in the urine of psychotic patients may be attributable to prolonged inactivity or malnutrition (Geller, Brill, Crumpton, Eiduson, Liston, and Mizrahi, 1962). This is unlikely to be the principal factor determining the low excretion rate of androstenol in our series, for a correlation with activity was sought for and not found, and patients who had obviously been malnourished (including alcoholics) were excluded. It is difficult to assess the influence of other environmental factors on the androstenol output in the urine of schizophrenics, as very few of these patients were tested more than once. However, the intra-individual variation of androstenol excretion as a whole in the group of patients tested was not greater than that in the controls and the reliability coefficients were very similar: on the other hand, 17-KS levels were much more variable. It is apparent that the output of androstenol was not affected by the clinical state or treatment of psychiatric patients in general. The patients tested at the begining and end of a stay in hospital were suffering from predominantly affective illnesses and were discharged in remission, yet no marked change in the urinary androstenol level had occurred. Moreover, no obvious association between androstenol excretion and any particular form of treatment was observed. Probably the most important point is that, with the exception of two patients, percentage fluctuations in androstenol output were large only in the low range (under about $0.5 \mathrm{mg}$./ 
$24 \mathrm{hr}$.), where experimental error would be contributing considerably to the total variance.

It is tempting, therefore, to postulate that the phenomenon of low androstenol excretion rate in schizophrenics is not a secondary consequence of the illness or its treatment, but is a constitutional factor allied to the physical, and possibly endocrine, features already associated by some with a predisposition to schizophrenic psychosis (Bleuler, 1954 ; Mayer-Gross, Slater, and Roth, 1960). In this investigation no systematic attempt was made to correlate measurable constitutional parameters with androstenol excretion rate in the patient series. Superficially no parallel trends could be discerned between a physical habitus or personality features which might be associated with androgen lack on the one hand and low urinary androstenol on the other, but such an association should obviously be sought for by objective methods in any future study. The correlations determined in the control group are not illuminating. The positive correlation between body-surface area and androstenol excretion rate in normal male subjects was not unexpected in the light of the findings of Tanner, Healy, Whitehouse, and Edgson (1959) of correlations of the same order with total urinary $17-\mathrm{KS}$.

\section{Summary}

The urinary excretion of $\Delta^{16}$-androsten- $3 \alpha$-ol of 69 male psychiatric patients aged 18 to 45 years has been compared with that of 112 healthy men in the same age range. The patients were divided into two main groups, those in whom at least some signs of schizophrenia were present (schizophrenics) and those in whom definitely no signs of schizophrenia were apparent (non-schizophrenics). The patient group as a whole excreted less androstenol than did the control group of healthy men, the mean levels being $1.24,0.86,0.63$, and $1.07 \mathrm{mg} . / 24 \mathrm{hr}$. respectively for the control, all-patient, schizophrenic, and nonschizophrenic groups. Statistical analysis of the difference between the means for the several groups showed that the phenomenon of low androstenol excretion was particularly associated with the schizophrenic group.

Mean 17-oxosteroid (17-KS) excretion was not significantly different between the groups, being 14.6, 12.8, 12.7, and 13.1 $\mathrm{mg} . / 24 \mathrm{hr}$. respectively for the control, all-patient, schizophrenic, and non-schizophrenic groups. The statistical comparison between urinary androstenol and 17-KS indicated that there was a polynomial, or exponential, relation between the two parameters, in both the control and patient series, the possible biological significance of which is put forward.

The phenomenon of low androstenol excretion in the psychiatric patients appears to be a constitutional factor, for the levels of androstenol, unlike those of 17-KS, in the urine in both the control and patient series showed relatively little intra-individual variation and appeared to be unaffected by clinical state, treatment, or other environmental changes.
We would like to express our gratitude to Dr. B. L. Mallett for invaluable assistance in initiating this investigation; to the consultant psychiatrists, York Clinic, Guy's Hospital, and the Maudsley Hospital, and to Dr. A. J. Coppen, of St. Ebba's Hospital, Epsom, for their collaboration in the collection of urine specimens and psychiatric data from their patients; to Miss $T$. Julian for her advice on statistical matters; to Miss Jane Bradley, Mrs. Louise Cuzner, and Mr. A. J. Rippon for skilled technical assistance; to the great number of volunteers who supplied 24-hour urine specimens ; and to Professor G. A. D. Haslewood for his inspiration to undertake the investigation.

\section{REFERENCES} Batt, J. C., Kay, W. W., Reiss, M., and Sands, D. E. (1957). F. ment.

Bleuler, M. (1954). Endokrinologische Psychiatrie. Thieme, Stuttgart.

Brooksbank, B. W. L. (1962a). F. Endocr., 24, 435.

(1962b). Lancet, 2, 150.

and Haslewood, G. A. D. (1950). Biochem. 7., 47, 36. (1961). Ibid., 80, 488.

Bulbrook, R. D., Thomas, B. S., and Brooksbank, B. W. L. (1963). 7. Endocr., 26, 149.

Dobriner, K. (1954). 7. clin. Invest., 33, 222.

Eysenck, H. J. (1959). Manual of the Maudsley Personality Inventory. London. Geller, E., Brill, N. Q., Crumpton, E., Eiduson, S., Liston, E., and
Mizrahi, L. (1962). Arch. gen. Psychiat., 6, 384.

Gower, D. B. (1963). f. Endocr., 26, 173.

- and Haslewood, G. A. D. (1961). Ibid., 23, 253.

Hatotani, N., Ishida, C., Maeda, M., and Waka, T. (1960). Recent Adv. Res. Nerv. System (Tokyo), 4, 704. Excerpta Med., 1960, Sect. VIII, 15, No. 3538 .

Hawk, P. B., Oser, B. L., and Summerson, W. H. (1947). Practical Physiological Chemistry, 12th ed. Blackiston, Philadelphia.

Hoskins, R. G. (1943). Psychosom. Med., 5, 3.

- and Pincus, G. (1949). Ibid., 11, 102.

Kappas, A., and Gallagher, T. F. (1960). F. clin. Invest., 39, 620.

Mather, K. (1949). Statistical Analysis in Biology, 3rd ed. Methuen, London.

Mayer-Gross, W., Slater, E., and Roth, M. (1960). Clinical Psychiatry, 2nd ed. Cassell, London.

Medical Research Council (1963). Lancet, 1, 1415.

Mittelman, A., Romanoff, L. P., Pincus, G., and Hoagland, H. (1952). ¥. clin. Endocr., 12, 831 .

Pincus, G., Hoagland, H., Freeman, H., Elmadjian, F., and Romanoff, L. P.' (1949). Psychosom. Med., 11, 74.

Reiss, M. (1958). Psychoendocrinology. Grune and Stratton, New York. and Stitch, S. R. (1954). 7. ment. Sci., 100, 704.

Rey, J. H., and Coppen, A. J. (1959). Brit. med. 7., 2, 1445.

- Nicholson-Bailey, U., and Trappl, A. (1957). Ibid., 2, 843.

Sands, D. E. (1957). In Schizophrenia : Somatic Aspects, edited by D. Richter, p. 77. Pergamon, London.

Snedecor, G. W. (1956). Statistical Methods. Iowa State Press, Ames, Iowa.

Stylianou, M., Forchielli, E., and Dorfman, R. I. (1961). F. biol. Chem., 236, 1318.

Tanner, J. M. (1955). Growth at Adolescence, Blackwell, Oxford.

Healy, M. J. R., Whitehouse, R. H., and Edgson, A. C. (1959). 7. Endocr., 19, 87.

Wakoh, T. (1959). Mie med. 7., 9, 351.

Wilson, H., Lipsett, M. B., and Korenman, S. G. (1963). F. clin. Endocr., 23, 491 . 